\title{
Development of a Revenue Model for Buyers in Co-Creation Environment
}

\author{
Young Jae Park \\ Department of Management Information Systems, Tongmyong University,428 Sinseon-ro Nam-gu, Busan, 48520, Republic of Korea \\ E-mail:yjpark@tu.ac.kr
}

\begin{abstract}
With the advancement of information communications technology (ICT) and dissemination of mobile devices, new businesses are constantly emerging, and collaboration and cooperation between suppliers and consumers are also leading to innovation. Furthermore, to enhance consumer loyalty or to attract new customers, marketing activities are further advancing by utilizing cutting-edge information technology. In particular, user experience is highly emphasized, influencing the stages of planning and developing products, and is even used as a means of marketing. Creating new value and joint innovation through direct customer engagement is indeed a new challenge from design to production, marketing, sales, and delivery of products or services. Personal information on the internet is rapidly increasing due to the advancement of information technology which leads to an increasing use of social networking services and web search, as well as easier access to the internet itself. More companies are attempting to link corporate strategies to the analyses of such personal information and customer propensity or preferences, which is considered key to corporate success. As such, the mobile environment has become a new business tool and channel for sales and purchase for both companies and customers, and new business models to utilize mobile devices are emerging. Services can use the user location to provide information on the areas or shops near the user. User profile can also be provided to advertisers and product sellers, and the advertisers can advertise products that certain users may be interested in based on the user profiles. Users can compare the lowest prices and get information on the related or similar products. This study suggests a buyer revenue model based on such scenario and reviews the technical issues in implementing the model.
\end{abstract}

Keywords - co-creation; RFID; business model; mobile business; e-word-of-mouth effect.

\section{INTRODUCTION}

In a modern world where businesses compete with the speed, the ability to quickly create and offer new value to customers or relevant stakeholders directly impacts the survival of companies. As global competition becomes greater and fiercer, innovation is a must to respond to quickly-changing stakeholder needs, and businesses are under pressure to further their active stance in developing organizational capabilities. Moreover, the overflow of new ideas that go beyond the region, national borders, and time and space, as well as the advancement of information technology that enables the sharing of ideas and knowledge, are driving organizations to be equipped with innovative systems in a globally competitive era.

Recently, our lives are changing in many different areas as mobile devices such as smartphones and tablets meet the latest information technology. With mobile devices, we now have access to the internet anywhere, anytime. We can search and get information, and even purchase and pay for products and services. As application services on mobile devices are highly emphasized, mobile phones play a crucial role in the mobile business process. Moreover, "apps," application programs on smartphones, are required to have a greater level of flexibility, applicability, scalability, and autonomy. Mobile app was regarded as one of the indispensable actors involved in value co-creation [1]. Wong et al. consider opportunities that mobile technologies introduce to further develop co-creation [2].

Mobile devices such as smartphones are combined with various technology and functions from user location-based context-aware services, social networking, information search and retrieval, RFID (Radio Frequency Identification), NFC (Near Field Communication), mobile commerce, mobile payment, messaging, e-mail, video and music play, and even object recognition which recognizes surrounding information including certain objects a user is interested in. With the advancement of such technologies, mobile devices can now be connected to the internet regardless of user location and time, enabling online financial institutions or shopping malls to develop application programs for mobile devices. Users can use their mobile devices to purchase or use products or services anytime, anywhere, and companies are furthering the application of the latest technology to 
enable users to purchase their products and services more easily and safely with mobile devices.

Meanwhile, due to the association of mobile devices and wireless communication technology, research is underway to create new $\mathrm{O} 2 \mathrm{O}$ models by seamlessly connecting offline products and online digital content based on mobile devices including smartphones. Also, with the advancement of information technology, more use of web search, ease of access to the internet, and personal information is rapidly increasing online. As such, an increasing number of businesses are trying to analyze personal information and customer propensity or preferences and link the analyses to their corporate strategy, it being considered key to their success.

Thus, mobile devices have become a new business tool as well as a channel for sales and purchasing for companies and customers. Like the spread of the internet led to new business models such as reverse auctions or group purchasing in the past, new business models are once again emerging using mobile devices where latest technology are developed and applied.

New information technology enables new types of businesses, and changes in company-customer relations due to new technology creates a cycle of promoting the development of new elementary technology. Therefore, for a virtuous cycle of the advent of new businesses and development of technology, various information technologybased business models need to be discovered and implemented.

As companies and individuals are connected to a digitalbased structure today, the relationship between companies and individuals have also changed. In the past, companies were the value creators and customers were their targeted consumers. However, today, customers are engaging more in core corporate processes which has led companies and customers to make joint efforts to create new value. In other words, this is a paradigm shift from producer-oriented to consumer-oriented management. While the role of producers and consumers were clearly differentiated traditionally, today, the boarder between the two parties is becoming obscure. Consumers are influencing the decisions made by companies through various means, and companies are also trying to further engage consumers to their production activities.

Today, innovation is a boom throughout all corners of society. In particular, innovation in management has long been considered as a must for companies to pursuit profit and gain competitiveness. Management innovation techniques have constantly been advancing in line with changes in the environment. In particular, as the concept of value shifted from company-oriented to customer-oriented, companies have moved from closed innovation to open innovation. Now going beyond corporate value chain to value ecosystem, various innovation techniques and concepts are emerging.

The value of products or services is not determined by providers but the customers who experience and use it. This is possible because the advancement of ICT has led to more opportunities for customers to create and share experiences. Moreover, innovation doesn't simply happen through cooperation within the existing value chain; cooperation with new stakeholders beyond the existing value chain and value chain network lead to further innovation. In other words, companies are promoting a new type of management innovation through cooperation with not only those in the existing value chain network but various new or other stakeholders including those who were once competitors. Recent studies refer to the term "value co-creation" which includes such concept. Value co-creation is defined as a type of cooperation where various stakeholders participate to create and achieve new common values in various industries under a value ecosystem to meet greater customer desires.

Activities such as reflecting customer feedback and ideas to product planning and development is not new; it has been around for quite a long time. Today, companies reflect consumer requirements in product planning and development stages, and recently, consumers even plan and design the products they wish to purchase. Customers can also directly invest in products or services through crowd funding. The highly spotlighted user experience itself is a corporate asset, and it is also used as a means of marketing to promote products.

Likewise, the advancement of ICT is creating new business models and furthering buyer or consumer engagement to corporate activities. However, consumer purchasing behavior still dwells in the concept of simply consuming or spending. This study suggests a buyer revenue model in an environment of information technology advancement and customer value co-creation in which consumer purchases directly leads to marketing activities and revenue, without additional activities such as describing user experience.

\section{A. Co-creation}

Co-creation or value co-creation is a term first introduced by Prahalad and Ramaswamy which differs from the traditional concept of business-centered value creation accepted by customers in that businesses and customers create value together; this demonstrates the change in the paradigm of value creation [3]. Co-creation can be simply defined as all activities by producers and consumers in cocreating value and their execution. Actualized forms of cocreation can be categorized according to the industry, product and company, and the involvement of consumers. Chesbrough suggested openness and possibility of communication from three perspectives; platform business model, co-creation with customers, and open innovation [4]. The platform business model differs from the traditional method where only the supplier provided and instead, provides communicational platforms like Apple's App Store, allowing consumers to find their own solutions. Co-creation with customers is recognizing the customer as the central figure in service activities and entices their participation in all levels of the value chain including product design, production, sales, marketing, etc. and co-creating value. Open innovation utilizes the ideas, technologies, services, etc. from not only within the company but also those of customers and external professionals.

Gemser and Perks analyzed how the customer co-creation concept has been conceptualized and investigated in other studies [5]. Meanwhile, Ranjan and Read examined 
literature on co-creation identified 149 papers for concept and measurement [6].

\section{B. Business Model in Mobile and SNS Environment}

Business models are broad concepts, defined as representations of fundamental logic and strategic selections to create and obtain value within the value network. Timmer identified business model components as 1) the roles of participants in business and the structure of their value flow, 2) potential profit obtained by participants, and 3) profit for the business leader [7]. Rayport and Jaworski suggested 1) value proposal or value group, 2) market space product provision, 3) company's resource system for delivering products and services, and 4) financial model to generate profit. They also proposed a framework for business model development which comprised of 4 major levels; 1) core discovery of opportunity, 2) defining target customer, core benefit, capacity, 3) defining market space product provision, and 4) defining managerial resource system [8].

In the past, it was believed that new value was generated by enabling transactions between companies and customers through mechanisms such as efficiency, complementation, fixation, and novelty. This view focuses the companycustomer relationship on the company, i.e. the company creates value by providing the customer with products or services. Prahalad and Ramaswamy suggested that value creation occurs through co-creation experience which is obtained by the customer's interaction with a network participant, including the company [9]. The value cocreation experience for the customer is a personalized experience at a certain time, place, and situation. The customer's experience world is composed of the event, the context of the event, involvement, personal meaning, etc. Thus, providing environments and networks that allow a personalized co-creation experience is important. Activation of value co-creation experiences require active interaction between company and customer which is in turn facilitated by satisfying factors such as communication, approach, transaction risk assessment, transparency, etc. Nodal companies, which comprise experience networks by collecting elements from providers, partner businesses, customer communities, etc. that are required in providing services, are crucial for the provided environment to satisfy the customer's personalized interactions. That is, a system that can restructure real-time resources to accept the customer's demands or personalized co-creation experiences is vital. The customer will determine the price of payment for the selected experience upon reflecting their individual conditions and the market will be a place for co-creation experience, composed of these customers. With the provision of personalized value co-creation experiences, it is necessary to understand the change in business paradigms and seek business models.

Recent studies on co-creation under using mobile device or SNS environment are shown in Table 1 [10]-[14].

TABLE I

CO-CREATION IN MOBILE DEVICE OR SNS ENVIRONMENT

\begin{tabular}{|c|l|}
\hline Author & \multicolumn{1}{|c|}{ Object } \\
\hline Kang [10] & $\begin{array}{l}\text { To develop business model for the co-creation } \\
\text { of financial institutions in mobile environment }\end{array}$ \\
\hline
\end{tabular}

\begin{tabular}{|c|l|}
\hline $\begin{array}{c}\text { Lamboglia } \\
\text { et al. [11] }\end{array}$ & $\begin{array}{l}\text { To develop business Model for co-creation in } \\
\text { Smarter Universities }\end{array}$ \\
\hline $\begin{array}{c}\text { Morosan } \\
\text { et.al. [12] }\end{array}$ & $\begin{array}{l}\text { To develop and validate empirically a } \\
\text { conceptual model that recognizes the central } \\
\text { role of consumers' degree of value co-creation } \\
\text { in creating valuable service experiences using } \\
\text { mobile devices in hotels }\end{array}$ \\
\hline $\begin{array}{c}\text { Dennis et } \\
\text { al. [13] }\end{array}$ & $\begin{array}{l}\text { To examine consumers value co-creation via } \\
\text { several shopping channels including a traditional } \\
\text { out-of-home shopping channel and "smart" } \\
\text { channels where consumers use a computer, a } \\
\text { mobile phone, or social media }\end{array}$ \\
\hline $\begin{array}{c}\text { Chia-Hui } \\
\text { Yu et al } \\
\text { [14] }\end{array}$ & $\begin{array}{l}\text { To proposes a value co-creation circle and } \\
\text { explores the key factors for developing a } \\
\text { successful value co-creation circle on social } \\
\text { commerce platforms }\end{array}$ \\
\hline
\end{tabular}

\section{MATERIAL AND METHODS}

\section{A. Suggestions about the Platform for Co-creation}

S. G. Hong et al proposes a conceptual model of SNS platforms for co-creation considering utilization of applications and connections with cloud services and company systems [15].

To conduct case studies, they analyzed cases such as the My Starbucks Idea: MSI that Starbucks introduced in 2008; Quirky, introduced by a 24-year-old in the USA in 2009, which began with an aim to develop a social product through information exchange and cooperation using experience, ideas, and web platform; and the case of 4 Food where consumers can not only select their hamburger according to their preference but also design products.

The results of the case studies were as follows: First, value co-creation platforms should enable consumers and various participants to suggest ideas, share information, and communicate; Second, consumers should be able to suggest and evaluate ideas directly; Third, companies and consumers should be able to engage as equal players; Fourth, participants should be informed of the incentives provided according to their level of participation. Therefore, the platform should be an open structure that connects all stakeholders including companies, consumers, providers, and distributors; offer functions to enable consumers to participate in the stages of collecting opinions, developing new products, and production; and must be connected to systems both in and out of the company.

In order to design a platform that reflects on the abovementioned topics, data accumulation and analytical tools necessary in identifying business areas and potential customers need to be supported. Analytical tools including data mining or big data analysis are also required to identify the activity process and demands of potential customers. A typical example of experience space is the SNS. Connection to the company's backbone system and legacy system such as SCM (Supply Chain Management) for information exchange and sharing among providers, ERP (Enterprise Resource Planning) and DW (Data Warehouse) for internal capacity are also required.

Experience space is most essential in designing a cocreation platform through customer involvement. Customer networks like the SNS are among the most appropriate as the space of customers' involvement and experience. Open API 
(Application Program Interface) could be utilized to connect with the existing SNS or involvement space could directly provide through the web without using existing services. Among the recently cited from a web service perspective are SOAP (Simple Object Access Protocol) and REST (Representational State Transfer); SOAP is usually combined with WSDL (Web Service Description Language) to define the services interfaces and UDDI (Universal Description, Discovery and Integration) to provide service discovery; REST considers Web services as resources, which are used through given representations.

REST, a web system, can be summarized as UniformLayered-Client-Cache-Stateless-Server. Web clients such as web browsers make and receive answers for requests for resources though resource identifiers like URL links. The request results are given in forms such as new contents displayed on the browser screen. This process invokes a transfer of the browser's representational state. REST is a term that states such characteristic and is more easily used than SOAP. The study by Pautasso et al. included a more detailed comparison of the two. Major web corporations such as Amazon, eBay, and Yahoo mostly provide RESTtype open API and Google has stopped providing SOAPbased API.

The SNS or Web Service of the customer network and those of the supplier network are not different but the same space. That is, co-creation by the customer and supplier are conducted within the same space. In using existing SNS, necessary applications can be developed and utilized through open API opened by the company providing the services including log-in, search, survey, statistics, etc. However, provided API alone can be limited and in circumstances that require an independent involvement space suited to the business model, a REST-based Web Service may be composed. Specifically, as involvement of co-creation is proportional to direct involvement in product development, various resources and tools essential in product development must be shared and provided. For example, support and provision of design tools, necessary components, provider lists etc., for product design are required. In such situations, building an independent system may be preferred to utilizing pre-existing SNS.

Information shared through involvement space is connected to the company's internal backbone systems and these are provided to the supplier networks. As nodal companies perform this function, platforms may be provided by the nodal companies. In the highest category of cocreation, product development, production, sales, and marketing are performed together. Therefore, a platform that secures interactive dialogue, access convenience, and transparency is required and real-time restructure of resources must be available. If customers cannot access the same level of information of companies and without information transparency, interactive communication may become difficult. In this context, access privilege and transparency are essential in meaningful conversations. With these elements secured, customers can evaluate the risks and effects of their decisions and actions, allowing co-creation to be actualized. All these factors should be considered and reflected in developing platform.

\section{B. Scenario for Buyer Revenue Model}

Magretta assimilated drafting a business model to composing a story: Just like a story that consists of characters, personalities, and roles, business models also consist of respective elements [16]. The fallowing scenario is based on such logic, describing a daily routine of university student "Michael."

1) "Michael," a college student, arrives at school. Upon "A" arriving at school, his schedule including the timetable for the day is displayed on "A's" smartphone.

2) "Michael" goes to the classroom for class. "Michael" places his mobile phone on the reader installed in the entrance. The classroom door opens and "Michael" can go in and take the class.

3) Once class is over, "Michael" heads to the school cafeteria with friends for lunch. The cafeteria menu is displayed on "Michael's" mobile phone, and "Michael" can check additional information such as the ingredient and price for each menu.

4) Once selecting the menu and making the payment with his smartphone, a meal ticket is issued on "Michael's" smartphone. "Michael" places his smartphone on the reader, and the food is provided as ordered.

5) During lunch with friends, "Michael" spots his friend's bag which he likes. When "Michael" places his smartphone close to the bag, he can get relevant information of the bag.

6) A search app opens, and "Michael" can view the list of stores that sell the bag at the lowest prices. Based on his location information, "Michael" can view the distance, contact information, route, and traffic information of the different stores. "Michael" adds the product and stores to his favorites list, and uploads a post on his social network account that he wants to purchase the product.

7) While drinking coffee after lunch, "Michael" receives a notification on similar products, so "Michael" searches the suggested products.

8) "Michael" takes his remaining classes and comes home. "Michael" gets another notification on his smartphone which was information on shoes. "Michael" remembers that he searched for shoes during lunch time. "Michael" reads the information on various products and finishes the day.

There are some prerequisites for the scenario above. First, to know that "Michael" arrived at school, the classrooms, and cafeteria, the user's location information must be provided. If location-based services are available, many other additional services can be provided as well. The services can obtain information such as the event of arriving at school, leaving school, staying within the campus, etc., and this information can be used to provide other various services. Second, an RFID tag must be attached on the friend's bag. The latest image processing technology enables users to obtain various information using photos, but it is not yet enough to find the exact model for products like bags. Attaching RFID tags may accompany issues such as personal information or privacy, and these are issues to be resolved.

First, the issue of location information. The recent trend seems to be allowing the provision of location information to service providers under the condition that the service is used by the information provider. The second issue of RFID tags 
can be resolved by preventing personal information leaks or privacy issues. If the tags do not store personal information and stores information on the product only, and provide incentives accordingly, attaching RFID tags won't be an issue. In other words, when the buyer purchases a product, the seller can attach RFID tags on the purchased product so the product information can be provided to a third party, and when and if the product is sold through the RFID tag, the initial buyer is notified that an incentive will be given. In this scenario, when a third person buys the product through an RFID tag, the product seller provides an incentive to the initial buyer of the product. This creates a buyer revenue model.

\section{RESULTS AND DISCUSSION}

\section{A. Business Model Diagram}

Fig. 1 is a business diagram of the above scenario. Table 2 is a summary of the role, offered values, and potential benefits of each participant in the scenario presented in this study, according to Timmer's definition [7].

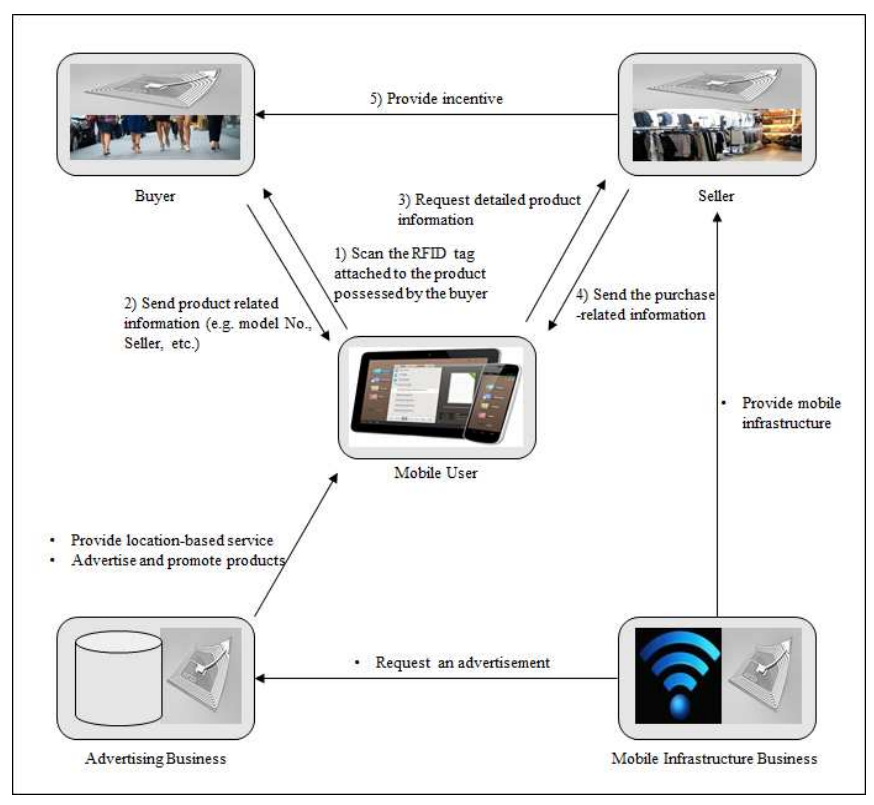

Fig. 1 Business Model Diagram

TABLE II

THE ROLES AND PROFITS

\begin{tabular}{|c|l|l|}
\hline Participant & \multicolumn{1}{|c|}{ Role } & \multicolumn{1}{c|}{ Profit } \\
\hline Mobile User & $\begin{array}{l}\text { Provide location } \\
\text { information }\end{array}$ & $\begin{array}{l}\text { Buy product at the most } \\
\text { reasonable price. } \\
\text { Obtain information of } \\
\text { interest. }\end{array}$ \\
\hline $\begin{array}{c}\text { Mobile } \\
\text { Infrastructure } \\
\text { Business }\end{array}$ & Build infrastructure & $\begin{array}{l}\text { Receive advertising fees or } \\
\text { (and) sales commission. }\end{array}$ \\
\hline $\begin{array}{c}\text { Advertising } \\
\text { Business }\end{array}$ & $\begin{array}{l}\text { Advertise and } \\
\text { promote products }\end{array}$ & $\begin{array}{l}\text { Obtain a new marketing } \\
\text { channel. }\end{array}$ \\
\hline Seller & $\begin{array}{l}\text { Attach a RFID tag } \\
\text { to a product }\end{array}$ & Obtains a new sales channel. \\
\hline Buyer & $\begin{array}{l}\text { Advertising model } \\
\text { role by exposing his } \\
\text { own product }\end{array}$ & $\begin{array}{l}\text { Receive advertising fees or } \\
\text { (and) sales commission. }\end{array}$ \\
\hline
\end{tabular}

Mobile users have a potential benefit or incentive of having greater accessibility to one's own information, purchasing products at the lowest price, and obtaining relevant information. Mobile businesses provide the infrastructure and receive advertisement incentives and product sales incentives in return. Product sellers provide RFID tags, and can benefit product sales profit, secure new sales channels, gain access to user information, and enhance efficiency in user management. While bringing out advertisement projects, advertisers are given advertisement incentives as they secure new channels for advertisement. Product buyers receive incentives by becoming the so-called "walking advertisement model" as they expose themselves to third parties.

\section{B. The Architecture of Mobile Agent for Mobile Business}

Previous studies have proved that no technical issues remain in using RFID tags and readers with mobile devices. However, the mobile businesses in this study require location processing technology for location-based services and technology to collect user profile and product information which remains an unsolved problem.

First, a system is needed to determine a certain area or building access using location information or coordinates collected from mobile devices. However, most locationbased services using mobile devices are based on GPS data which makes it difficult to process data on access to a specific space or area. This is where the location tracking system comes in [17]. Information on particular buildings or areas are shown as MBRs (Minimum Bounding Rectangle) and each MBR is grouped and built into an R-tree index. Once the location coordinate is collected from a mobile device, the service searches for the closest MBR and calculates the shortest distance. The areas database consisting of MBRs store location data on various spaces. This enables services to compare the location data with the GPS coordinates of the mobile device, finds the closest space from the current location, and calculates, with spatial computing and algorithms, whether the user is entering or leaving the space. To calculate whether the user is entering or leaving a particular space or area, the service needs to receive regular location information from the mobile device. The service can determine whether the user is entering or leaving a particular space through spatial computing by using the previous and current location information.

Also, to collect user profile and enable price comparison function, the search and mobile agent technology muse be available. The scenario in this study requires one for the user's mobile device and another for the mobile businesses. Dual mobile agents for mobile businesses currently offer price comparison and information search functions, and has no technical issues. However, they do require a conceptual design of the system structure. Fig. 2 shows the conceptual structure of the search and mobile agent for mobile business. The index base stores information generated by the index generator and URLs (Uniform Resource Locator) that users enter. The search engine consists of keyword search algorithms that search addresses that meet the requirements of users or other agents. 


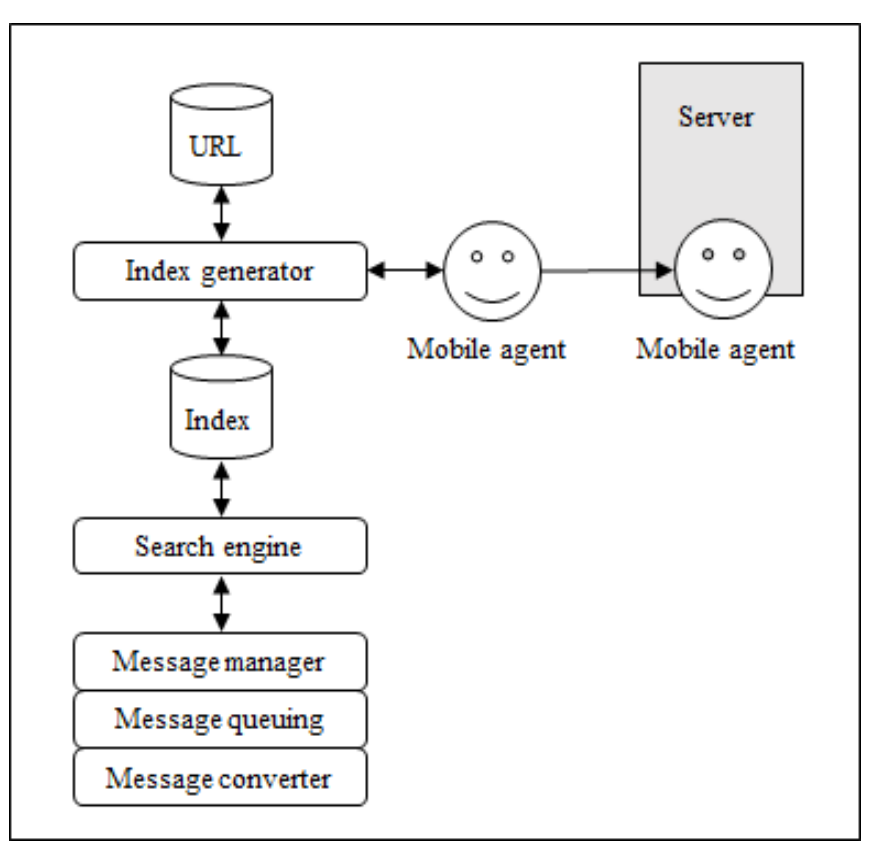

Fig. 2 The Conceptual Architecture of Mobile Agent

Figure 2 above indicates that the general mobile agent operates as follows: First, the mobile agent collects pages from multiple servers simultaneously based on the URL database; the collected data is then converted into significant data through the index generator, and saved to the index base. This process is repeated. The communications module in charge of communication with other agents or systems consists of three parts. All messages come in and goes out through a "message converter," and are converted into TCP/IP protocols. The message converter also controls multiple simultaneous connection with other agents or systems. The "message queuing" module manages outbound and inbound message queues, and only the valid messages are let through. The "message manager" checks the adequacy of the message. It checks all layers of the KQML (Knowledge Query and Manipulation Language) message, initializes the interface engine, and creates a message that responds to the message query. KQML is a major language for agent communications to overcome the heterogeneity with other agents or systems [18].

\section{CONCLUSION}

In the era of digital convergence, mobile devices have become capable of doing almost everything we can do on personal computers. Even more, with mobility, mobile devices are creating new business models. In this study, buyers attach RFID tags provided by the product sellers onto the purchased product, making the buyer a product advertiser who then receives financial compensation by the seller. Mobile businesses identify the location of the mobile device user, identify whether the user entered or left a certain region or building, and provide the user with relevant information. Mobile businesses also profile the user's search history and provide the information to advertisers and product sellers. Advertisers bring out advertising activities by exposing information on products that a user may be interested in. Mobile businesses search and collect online information and provide the information to users by using mobile agents to provide information such as comparison of lowest prices and information on related or similar products. This study has suggested such business model and designed a conceptual structure of mobile agents for mobile businesses.

When and if the suggested business model and necessary technology is successfully developed and operated, the model and technology can be applied to many different areas. First is an example of its application in the technical aspect. Currently available location-based services provide information on tourist sites, hotels or restaurants with nearby buildings or stores based on random GPS coordinates. However, the location-based service suggested in this study can provide accurate information on the actual building that the smartphone holder entered or left. Such technology or service can be applied not only to the tourism industry but also to the distribution industry such as department stores, or the culture industry including theaters and performance centers. The scope of application is very broad and can lead to many other new businesses.

The model and technology can also be used in the business side. Currently, RFID tags are attached to products to check product authenticity, after-sales-services, and track distribution routes. However, in most cases, the RFID tags are removed once the product has been purchased, which makes it difficult for businesses to use the RFID tags for business purposes after the purchase has been made. As suggested in the scenario of this study, if an incentive is given to the buyer, the RFID tag can remain attached even after purchasing, which enables further and new business activities in the post-purchase stage. The greatest weak point now is that it is difficult to check the quality or condition of the actual product with the images or videos provided by online shopping malls or home shopping channels. If RFID tags remain attached even after the purchase, the company that attached the RFID tag on the product can view the list of customers who purchased the product, and compare the profiles or social network account of those who are willing to purchase their product, and even get information on who already has the product to prompt his/her friend to make the purchase as well.

However, this study could not suggest the statistical analysis or analysis model for empirical study. Therefore, future research needs to investigate the evaluation model to simulate the business model and conduct analysis through empirical study.

\section{ACKNOWLEDGMENT}

This Research was supported by the Tongmyong University Research Grants 2015(2015A033-1)

\section{REFERENCES}

[1] J. (Snow) Wu, R. Law and J. Liu, "Co-creating value with customers: a study of mobile hotel bookings in China," International Journal of Contemporary Hospitality Management, Vol. 30, Issue 4, pp. 20562074, 2018.

[2] T. Y. T. Wong, G. Peko, D. Sundaram and S. Piramuthu, "Mobile environments and innovation co-creation processes \& ecosystems," Information \& Management, Vol. 53, Issue 3, pp. 336-344, 2016.

[3] C. K. Prahalad and V. Ramaswamy, The Future of Competition: CoCreating Value with Customers, Harvard Business Press, USA, 2004. 
[4] H. Chesbrough, Open services innovation: Rethinking your business to grow and compete in a new era, San Francisco, CA: John Wiley \& Sons, 2010.

[5] G Gemser and H Perks, "Co-creation with customers: An evolving innovation research field," the Journal of Product Innovation Management, Vol. 32, Issue 5, pp. 660-665. 2015

[6] Kumar Rakesh Ranjan and Stuart Read, "Value co-creation: concept and measurement," Journal of the Academy of Marketing Science, Vol. 44, Issue 3, pp 290-315, May 2016.

[7] P. Timmers, "Business Model for Electronic Markets," Electronic Markets, Vol. 8, No. 2, pp. 3-8, 1999.

[8] J. F. Rayport and B. J. Jaworski, e-Commerce, McGraw-Hill, 2002.

[9] C. K. Prahalad and V. Ramaswamy, "The New Frontier of Experience Innovation,” Sloan Management Review, pp. 12-18, 2003.

[10] T. Kang, "A New Business model for E-commerce: T-commerce and Its Implications on Financial Institutions," Journal of Global Business and Trade, Vol. 12, No. 1, pp. 37-42, May 2016.

[11] R. Lamboglia, D. Mancini and P. Piedepalumbo, New Business Model for Value Co-creation in Smarter Universities, in Conference New Business Models - Toulouse Business School, Vol. 16, 17 June 2016.

[12] C. Morosan and A. DeFranco, "Co-creating value in hotels using mobile devices: A conceptual model with empirical validation," International Journal of Hospitality Management, Vol. 52, pp. 131142, January 2016.
[13] C. Dennis, M. Bourlakis, E. Alamanos, S. Papagiannidis and J. Joško Brakus, "Value Co-Creation Through Multiple Shopping Channels: The Interconnections with Social Exclusion and Well-Being," International Journal of Electronic Commerce, Vol. 21, Issue 4, pp. 517-547, 2017.

[14] Chia-Hui Yu, Chia-Chang Tsai, Yichuan Wang, Kuei-Kuei Lai and Mina Tajvidi, "Towards building a value co-creation circle in social commerce," Computers in Human Behavior, 2018. Available: https://doi.org/10.1016/j.chb.2018.04.021/

[15] S. G. Hong, H. J. Kim and H. R. Choi, "The Conceptual Model of a SNS Platform for Co-creation," Journal of the Korea Industrial Information System Society, Vol. 17, No. 3, pp. 95-104, 2012.

[16] J, Magretta, "Why Business Model Matter," Harvard Business Review, Vol. 80, No.5, pp. 86-92, 2005.

[17] B. Park, H. Choi, J. KIm, J. Lee, C. Kim, K. Lee, Y. Park and M. Park, "Real-Time Location Tracking System Suitable for Global Shipping Logistics," Journal of the Korean Institute of Information and Communication Engineering, Vol. 18, No. 5, pp.1207-1214, 2014.

[18] T. Finin, R. Fritzson., D. McKay and R. McEntire, "KQML as an Agent Communication Language", in Proc. of the Third International Conference on Information and Knowledge Management (CIKM94), pp.456-463, 1994. 